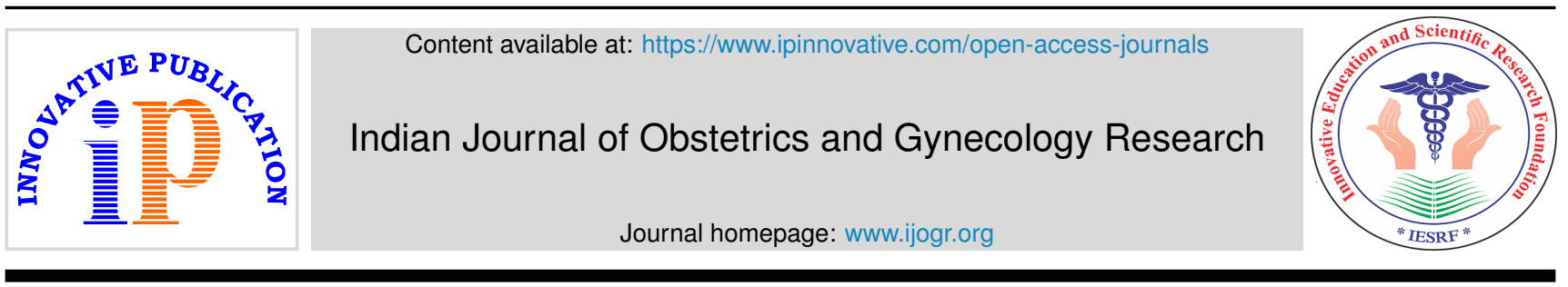

Original Research Article

\title{
Predictive value of thyroid stimulating hormone as a biomarker in intrauterine growth restriction
}

\author{
Shriya Ganju ${ }^{1, *}$ \\ ${ }^{1}$ Dept. of Obstetrics \& Gynaecology, Regional Hospital, Kullu, Himachal Pradesh, India
}

\section{A R T I C L E I N F O}

\section{Article history:}

Received 19-08-2020

Accepted 17-10-2020

Available online 13-03-2021

\section{Keywords:}

Biomarker

Thyroid stimulating hormone Intrauterine growth restriction

\begin{abstract}
A B S T R A C T
Background: Normal maternal thyroid function is essential for fetal growth and neurocognitive development. Intra uterine growth restriction (IUGR) is a complex condition arising from maternal, placental, or fetal mechanisms and any imbalance in thyroid function may lead to undesirable results for both mother and fetus.

Aims and Objective: The aim of this study was to co-relate the level of thyroid stimulating hormone (TSH) in clinically diagnosed cases of intra uterine growth restriction.

Materials and Methods: A prospective study was conducted in a tertiary care hospital for a period of one year in which one hundred and twenty consecutive clinically suspected cases of singleton IUGR pregnancies at 34-40 weeks of gestation were enrolled. The reference level of TSH during the third trimester was taken as 0.3 to $3.0 \mathrm{mIU} / \mathrm{L}$. The TSH levels were recorded and a descriptive analysis of the data was performed.

Results: Among the 120 clinically diagnosed cases of IUGR only three antenatal mothers from rural background had TSH levels below $0.3 \mathrm{mIU} / \mathrm{L}$. All three were vegetarians. In these, hypothyroid antenatal mothers, the delivery outcomes were; one was born dead while the other two babies were born alive and required caesarean section. However, the two born alive had a very low birth weight; less than $1.5 \mathrm{kgs}$ and both needed admission to neonatal intensive care unit.

Conclusion: Since the causation of IUGR is multifactorial, the role of TSH alone may not be accurate to be used as biomarker for prediction of IUGR.

(C) This is an open access article distributed under the terms of the Creative Commons Attribution License (https://creativecommons.org/licenses/by/4.0/) which permits unrestricted use, distribution, and reproduction in any medium, provided the original author and source are credited.
\end{abstract}

\section{Introduction}

Intra uterine growth restriction (IUGR) is a complex yet common fetal growth disorder encountered in modern obstetrics caused either due to an innate abnormality or some external adverse effects on the fetus. ${ }^{1}$ It constitutes a major clinical and public health problem, mainly in the developing world. ${ }^{2}$ IUGR is a clinical definition applied to neonates born with features of malnutrition and the estimated birth weight is less than the $10^{t h}$ percentile for the particular gestational age. ${ }^{3}$ Globally, it is estimated that IUGR affects $24 \%$ of the newborns, which account for around 30 million infants born annually. ${ }^{4}$ In the

\footnotetext{
* Corresponding author.

E-mail address: shriya.ganju@gmail.com (S. Ganju).
}

Asian continent approximately $75 \%$ of all infants born are IUGR. ${ }^{5,6}$ In India, the National Neonatal Perinatal database reports the incidence of IUGR to be $9.65 \%$ among hospital born live infants while a recent UNICEF survey estimates the incidence to be about $25-30 \%$. 4,7

The second most common endocrinologic disorders found in pregnancy are thyroid disorders. ${ }^{8}$ Hypothyroidism can be either overt or subclinical. In overt hypothyroidism, serum TSH levels are elevated $(\geq 10 \mathrm{mIU} / \mathrm{L})$ and T4/Free T4 (FT4) levels are low. In subclinical hypothyroidism the TSH level is $(\leq 10 \mathrm{mIU} / \mathrm{l})$ with normal Serum T4/FT4. Overt hypothyroidism is estimated to occur in $0.3-0.5 \%$ of pregnancies while subclinical hypothyroidism appears to occur in $2-3 \% .{ }^{8}$ During pregnancy because of increased metabolic demand, there is increased basal metabolic rate, 
increased secretion of thyroid hormone due to action of human chorionic gonadotrophin and human chorionic thyrotropin which share their molecular structure, as well as receptor cross-reactivity with $\mathrm{TSH} .{ }^{9}$ The prevalence of IUGR in overt hypothyroidism is $25 \%$ and $8 \%$ in subclinical hypothyroidism.

At present no preventive interventions are available to predict IUGR reliably, thus relevance of TSH as a biomarker for prediction of IUGR is plausible, the correlation of low levels of TSH in IUGR is evaluated.

\section{Materials and Methods}

This was a prospective, observational study, conducted in our tertiary care hospital over a period of one year from August 2017 to July 2018, and was approved by the college committee.A total of 120 consecutive clinically suspected cases of IUGR with singleton pregnancies at 34-40 weeks of gestation attending the hospital were enrolled in the study after taking an informed consent. The gestational age was determined on the basis of the date of last menstrual period or by first trimester ultrasound if available. The clinical diagnosis of IUGR was made on the basis of poor maternal weight gain and a non- correspondence with the period of gestation (fundal height less than the period of gestation). In all cases the serum TSH was done by automated chemiluminescence method and readings recorded.

\section{Results}

A total of 6533 live births were recorded in our tertiary care hospital from August 2017 to July 2018, and 120 consecutive women with singleton pregnancies having clinical suspicion of intrauterine growth restriction and a gestational age of 34 weeks or beyond were enrolled in the study. Approximately $70 \%(n=83)$ were from the rural background and $44 \%(n=51)$ were primigravida. The mean age of the subjects was 21.8 years \pm 3.1 SD. Forty two percent of the antenatal mothers were in the age group of $20-25$ years $(n=50)$ followed by $41 \%$ in the age group of $26-$ 30 years as shown in Table 1 . All the 120 study participants were non-smokers and non- alcoholics while $67.5 \%(n=81)$ were non-vegetarians.

Table 1: Age distribution in study population

\begin{tabular}{lccc}
\hline S. No & Age & $\begin{array}{c}\text { Number } \\
(\mathbf{n = 1 1 7})\end{array}$ & $\begin{array}{c}\text { Percentage } \\
(\boldsymbol{\%})\end{array}$ \\
1 & $<20$ years & 10 & $8 \%$ \\
2 & 21-25 years & 50 & $42 \%$ \\
3 & 26-30 years & 48 & $41 \%$ \\
4 & $>31$ years & 9 & $9 \%$ \\
\hline
\end{tabular}

The Body Mass Index (BMI) ranged from $14.2 \mathrm{~kg} / \mathrm{m}^{2}$ to $25.5 \mathrm{~kg} / \mathrm{m}^{2}$ with the average BMI being $19.93 \mathrm{~kg} / \mathrm{m}^{2}$ The BMI of $<18.5 \mathrm{~kg} / \mathrm{m}^{2}$ was observed in 28 underweight antenatal mothers $(23.3 \%)$ whereas only one $(1 \%)$ of the
Table 2: Demographic characteristics of the study population

\begin{tabular}{lccc}
\hline S. No & $\begin{array}{c}\text { Demographic } \\
\text { characteristics }\end{array}$ & $\begin{array}{c}\text { Number } \\
(\mathbf{n = 1 1 7})\end{array}$ & $\begin{array}{c}\text { Percentage } \\
(\%)\end{array}$ \\
1. & Rural & 83 & $70 \%$ \\
2. & Urban & 34 & $30 \%$ \\
\hline
\end{tabular}

Table 3: Body mass index of the study population

\begin{tabular}{llccc}
\hline S & BMI $(\mathbf{W t}$ & Reference & $\begin{array}{c}\text { Number } \\
(\mathbf{n = 1 2 0})\end{array}$ & $\begin{array}{c}\text { Percentage } \\
(\mathbf{\%})\end{array}$ \\
No. & $\left.\mathbf{h H t}^{2}\right)$ & & 28 & $23.3 \%$ \\
1. & Underweight & $<18.5$ & 1 & $1 \%$ \\
2. & Overweight & $>25$ & 91 & $75.8 \%$ \\
3. & Normal & $18.5-25$ & & \\
& weight & & & \\
\hline
\end{tabular}

subjects evaluated was overweight with a BMI of 25.5 $\mathrm{kg} / \mathrm{m}^{2}$ (Table 3). The average height of the subjects was $153.72 \mathrm{~cm} \pm 4.07 \mathrm{SD}$ and the average pre-pregnancy weight as recorded was $47.17 \mathrm{~kg} \pm 5.82 \mathrm{SD}$. Among 120 deliveries, 67 women had normal vaginal delivery while 53 underwent lower segment caesarean section.

Out of 53 caesarean delivery, 32 caesareans were done due to fetal distress out of which $26(49 \%)$ were conducted for non-reassuring fetal heart rate. Other causes were failed induction and poor Manning score. Forty-three neonates required admission to neonatal intensive care unit (NICU). The major cause was respiratory distress syndrome $(n=17)$ $39 \%$. Other causes for admission included hypoglycaemia, neonatal jaundice, and meconium aspiration syndrome in decreasing order. The neonates were admitted to NICU for about 2 to 5 days.

The TSH levels below $0.3 \mathrm{mIU} / \mathrm{L}$ was recorded in three antenatal mothers in the age-group of 26-30 years. All three antenatal mothers were from rural background and vegetarian. In these, one was born dead while the other two babies were born alive. The antenatal mother with normal BMI delivered live babies. However, the mode of delivery in the two born alive was LSCS due to fetal distress. Both neonates had a very low birth weight; less than $1.5 \mathrm{kgs}$ and required admission to neonatal intensive care unit for 2-5 days.

\section{Discussion}

During normal pregnancy, changes in thyroid function occur, however, information regarding outcomes of pregnancy with coexistent IUGR and hypothyroidism is scarce. Pregnancy influences the thyroid function and its dysfunction is associated with maternal and fetal morbidity while IUGR is also associated with adverse fetal outcomes. ${ }^{10}$ During pregnancy the maternal thyroid gland being under physiological stress results in an increase in thyroxine binding globulin, increased demand for iodine and thyroid stimulation by HCG. During first twelve weeks the fetus depends on mother for thyroxine 
hormone, thyroxine is transferred across placenta, and converted to triodothyronine. The thyroxin is needed for growth, brain and lung development. ${ }^{11}$ The borderline hypothyroid women, who conceive can become subclinical or overt hypothyroid during pregnancy. About $2-3 \%$ of pregnant women are hypothyroid, of whom $0.3-0.5 \%$ have overt hypothyroidism and $2-2.5 \%$ present subclinical hypothyroidism. ${ }^{12}$ In a study on the prevalence of thyroid diseases the authors report thyroid diseases greater in females as compared to males in the rural population though not statistically significant. ${ }^{13,14}$ In our study all three antenatal mothers where from the rural areas as well as vegetarians. ${ }^{14}$ Vegan diet tends to be associated with lower risk of hypothyroidism.Body Mass Index (BMI) significantly increases during pregnancy due to gain of weight with normal progression of pregnancy. In a study the BMI correlated positively with TSH level in first and second trimesters while it correlated negatively with FT4 level in second and third trimesters, but, failed to demonstrate significant association with FT3 level in any of trimesters in euthyroid pregnant women. ${ }^{15}$ In our study one antenatal mother had a low BMI while the two with live births had a normal body weight.

Early diagnosis and treatment of hypothyroidism in pregnancy is very essential. The main test mainly used to diagnose thyroid dysfunction is TSH. It is generally reproducible, reliable and available. The evaluation of the results is important as it requires trimester specific reference ranges so as not to underestimate hypothyroidism and /or overestimate of hyperthyroidism. The TSH reference range is based on "Guidelines of the American Thyroid Association for the Diagnosis and Management of Thyroid Disease During Pregnancy and Postpartum," established in 2012. The upper limit for TSH is taken as $2.5 \mathrm{mIU} / \mathrm{L}$ in the first trimester, and $3.0 \mathrm{mIU} / \mathrm{L}$ in the second and third trimesters, while the lower physiological limit is considered to be $0.1 \mathrm{mIU} / \mathrm{L}$ in the first trimester, $0.2 \mathrm{mIU} / \mathrm{L}$ in the second, and $0.3 \mathrm{mIU} / \mathrm{L}$ in the third. ${ }^{16,17}$ In a study on fetal outcome in hypothyroid women conducted by Ruchi Kishore et al reported that $13 \%$ were IUGR in hypothyroid patients $6.2 \%$ were IUD ${ }^{18}$ Several authors have performed cordocentesis for fetal blood sampling in babies affected by severe IUGR and have reported a statistically significant reduction in circulating concentrations of free $\mathrm{T} 4$ and free T3. In our study we took TSH as the standard and in three the levels were below $0.3 \mathrm{mIU} / \mathrm{L}$. Out the three one was born dead. The two born live were delivered by LSCS because of fetal distress. In both neonates the birth weight was less than $1.5 \mathrm{kgs}$ and required admission to neonatal intensive care unit.

Biomarkers as predictors of IUGR has been quite a research interest. IUGR results from multifactorial causes. Serum metabolites for prenatal screening of aneuploidy and open neural tube defects, either individually or in combination has been proposed but the predictive efficacy has not been adequately evaluated in a systematic manner. TSH as a biomarker for IUGR in combination could be of value. Overt hypothyroidism (TSH greater than 10 $\mathrm{mIU} / \mathrm{L}$ and/or low FT4) is treated in pregnant women, but the approach to subclinical hypothyroidism is more complicated because the harms and benefits are not well established. These uncertainties have led to disagreement on whether women should be screened for thyroid disease in pregnancy or not.

\section{Conclusion}

Many studies indicate a possible effect of thyroid dysfunction and IUGR. However, the results between studies are variable, and drawing clear cut conclusions is difficult though it is widely accepted that overt hypothyroidism increases the risk for deleterious outcomes and the risk for IUGR. Thus, the performance of the TSH as an individual biomarker has limited clinical utility for predicting IUGR. Large multicentric study with reference standards at various trimesters should be conducted to better understand these cross talks.

\section{Source of Funding}

None.

\section{Conflict of Interest}

None.

\section{References}

1. Faraci M, Renda E, Monte S, Prima FD, Valenti O, Domenico RD, et al. Fetal growth restriction: current perspectives. J Prenat Med. 2011;5(2):31-3.

2. Sharma D, Shastri S, Sharma P. Intrauterine Growth Restriction: Antenatal and Postnatal Aspects. Clin Med Insights Pediatr. 2016;10:67-83. do1:10.4137/cmped.s40070

3. Sharma D, Chandnani K. Clinical study of IUGR cases and correlation of Doppler parameters with perinatal outcome. Int J Reprod, Contracept Obstet Gynecol. 2016;5:4290-6. 10i: $10.18203 / 23200$ 1770.i1rcog20164330.

4. United Nations Childrens Fund and World Health Organization, Low Birth weight: Country, regional and global estimates. New York, USA 2004.

5. Onis MD, Blössner M, Villar J. Levels and patterns of intrauterine growth retardation in developing countries. Eur J Clin Nutr. 1998;52:5-15.

6. Singh M. Disorders of weight and gestation. In: Singh M, editor. Care of the Newborn. vol. 1999. New Delhi: Sagar Publications; 1999. p. $224-45$.

7. Kady SM, Gardosi J. Perinatal mortality and fetal growth restriction. Best Pract Res Clin Obstet Gynaecol. 2004;18(3):397410. doi:10.1016/j.bpobgyn.2004.02.009.

8. Ramprasad M, Bhattacharyya SS, Bhattacharyya A. Thyroid disorders in pregnancy. Indian J Endocrinol Metab. 2012;16(2):167-70.

9. Khadilkar S. Thyroid-Stimulating Hormone Values in Pregnancy: Cutoff Controversy Continues? J Obstet Gynecol India.

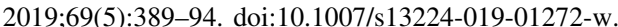

10. Sahu MT, Das V, Mittal S, Agarwal A, Sahu M. Overt and subclinical thyroid dysfunction among Indian pregnant women and its effect on 
maternal and fetal outcome. Arch Gynecol Obstet. 2010;281(2):21520. 101:-1007/s00404-(0)0-105-11

11. Saki F, Dabbaghmanesh MH, Ghaemi SZ, Forouhari S, Omrani GR, Bakhshayeshkaram M. Thyroid Function in Pregnancy and Its Influences on Maternal and Fetal Outcomes. Int J Endocrinol Metab. 2014;12(4):19378. do1:10.5812/1jem.19378.

12. Cignini P, Cafà EV, Giorlandino C. Thyroid physiology and common diseases in pregnancy:review of literature. J Prenat Med. 2012;6(4):64-71.

13. Padmanabhan P. Study of thyroid profile estimations by immunodiagnosis in rural population. GJRA. 2019;8(3):3970-5.

14. Tonstad S, Nathan E, Oda K, Fraser G. Vegan Diets and Hypothyroidism. Nutrients. 2013;5(11):4642-52. dol:10.3300/nus 14642

15. Kumar S, Chiinngaihlun T, Singh MR, Punyabati O. Correlation of Body Mass Index (BMI) with Thyroid Function in Euthyroid Pregnant Women in Manipur, India. J Clin Diagn Res. 2017;11(4):13-5.

16. Stagnaro-Green A, Abalovich M, Alexander E, Azizi F, Mestman J, Negro R, et al. American Thyroid Association Taskforce on Thyroid Disease During Pregnancy and Postpartum. Guidelines of the American Thyroid Association for the diagnosis and management of thyroid disease during pregnancy and postpartum. Thyroid. 2011;21(10):1081-1125.

17. Alexander EK, Pearce EN, Brent GA. Guidelines of the American Thyroid Association for the Diagnosis and Management of Thyroid Disease During Pregnancy and the Postpartum. Thyroid. 2017;27:31589.

18. Kishore R, Mishra N, Yadav J. Hypothyroidism in pregnancy and its impact on maternal and fetal outcome. J Evol Med Dent Sci. 2015;4(79):13849-55. doi:10.14260/jemds/2015/1973.

\section{Author biography}

Shriya Ganju, Medical Officer

Cite this article: Ganju S. Predictive value of thyroid stimulating hormone as a biomarker in intrauterine growth restriction. Indian $J$ Obstet Gynecol Res 2021;8(1):53-56. 